\title{
LOS DERIVADOS SUFIJALES EN -BLE EN ESPAÑOL
}

1. El objetivo del presente trabajo es analizar un aspecto particular del amplio dominio de la formación de las palabras en español: la derivación de adjetivos mediante el sufijo -ble ${ }^{1}$.

Tal propósito comprende, de una parte, el estudio de la transmisión del latín al romance y la situación de dichos derivados en las primeras etapas de formación de la lengua, y, de otra, el análisis de los valores que atribuye el formante -ble al adjetivo y los factores que determinan los mismos.

2. El sufijo latino -BlLIS se une inicialmente a raices verbales (ACBPTĀBłLIS, CREDIBILIS) y después a temas participiales (COMPREHENSIBILIS) ${ }^{2}$. Cobra vitalidad con los autores cristianos $y$, en general, en latín medieval ${ }^{3}$. Esta fecundidad es heredada por sus derivados romances occi-

1 Prescindimos del examen de la prefijación negativa de estos adjetivos, que plantea otros problemas, principalmente en lo que respecta a las modificaciones de sentido que entranan para los derivados.

2 También se añade, aunque raramente, a términos nominales (PERniciabrLrs). Véase F. Dirz, Grammaire des langues romanes, 3tme éd., Paris, L. A. Franck, 1874, vol. II, pág. 304 (citamos por la reimpresión de Genève-Marseille, Slatkine ReprintsLaffitte Reprints, 1973) y F. HaNssBN, Gramática historica de la lengua castellana, Paris, 1966, § 332.

3 Véase Charles H. Grandgent, Introducción al latín vulgar, 4." ed., Madrid, C. S. I. C., 1970, \& 39 y W. MEYER-LtbKR, Grammaire des langues romanes, Paris, 1890-1906 vol. II, \& 408 (citamos por la reimpresión de Geneve-Marseille, Slatkine Reprints - Laffitte Reprints, 1974).

LXI. -13 
dentales 4: -vel en portugués ${ }^{5}$, -bile (culto) y -évole (popular) en italiano ${ }^{6}$ y -ble en francés ${ }^{7}$, catalán y español.

2.1. Independientemente de esta frecuencia de uso interesa destacar la variedad de posibilidades significativas del sufijo latino. La mayoría de los adjetivos en -BIllis son derivados de verbos transitivos y expresan posibilidad, necesidad $u$ obligación desde una perspectiva pasiva: AUDIBÍlLIS, 'que puede ser oído'; CRĒDIBĺlLIS, 'que debe ser creído'. Pero los hay también que, siendo susceptibles de expresar posibilidad o no, tienen valor activo: capabilis, 'que puede contener' o 'que contiene'. $\mathrm{Si}$ el verbo de base es intransitivo, el adjetivo derivado tiene asimismo valor activo y concuerda, no ya con el objeto, sino con el sujeto de la oración que configura el verbo primitivo; sin embargo, parecen quedar excluidos los contenidos de posibilidad o necesidad: DURABÍlis, 'que dura'. Otro de los sentidos de estos adjetivos, y para F. Hanssen el más antiguo, es el instrumental. Éste se halla en ejemplos como el siguiente de Plauto, DATE OPERAM ADIUTABILEM, en el que OPERA ADIUTABILIS no significa OPERA QUAE ADIUTET sino OPERA QUA ADIUTETIS ${ }^{8}$. También F. Hanssen propone como significado de tales derivados el causal. Este se presentará en adjetivos como TERRIBILIS, HORRIBILIS 9.

4 En rumano, si bien existe el sufijo -bil, carece de la vitalidad de los correspondientes en otras lenguas romances. Véase W. MEYER-LUtBKE, ob. cit., § 408 y MARIA IlIzscu, «Sufixul adjectival -bil în limba română, Studii şi materiale privitoare la formarea cuvintelor în limba română, I, 1959, págs. 8496.

5 Véase Joseph H. D. Allen JR., Portuguese word-formation with suffixes, New York, Kraus Reprint Corp., 1966, § 112.

6 Véase P. TaxnvěıZ, Grammatica storica dell'italiano, Bologna, Il Mulino, 1972, vol. III, $\$$ 15941604; G. RoHLFs, Grammatica storica della lingua italiana e dei suoi dialetti, Torino, G. Einaudi, 1969, vol. III, $\$ \S 1035-1036$ y 1150 y, desde el punto de vista generativo-transformacional, GrazIA ATTILI, «Gli argettivi in -bile: un'analisi semantica», Lingua e stile, XII:2, 1977, págs. 185-199.

7 Véase E. StaAp, «Le développment phonétique de -abilis et -ibilis en français», Studier i Modern Sprdkvetenkap utg. av Nyfil. Sallsk. i Stockholm, V, 1914, páginas 117-130; Eva THORNB, Le développment de sens du suffixe latin in k-bilis» en français, Lund, Hakkan Ohlssons Boktryckeri, 1942; JBAN Dubors, Etude sur la dérivation suffixale en français moderne et contemporain, Paris, Larousse, 1962, páginas 52 y 53. Para una visión somera de la introducción y arraigamiento de -able en inglés puede consultarse: Hans Marchand, The Categories and Types of Present-Day English Word-Formation, 2." ed., München, C. H. Beck, 1969, \$\$ 4.2.1.4.2.11., exposición basada en F. Gall, On English Adjectives in "able», London, 1877.

8 F. HANSSBN, «Die Aktivbedeutung der Adjektiva auf bilis im archaischen latein», Philologus, 47, 1889, págs. 274290 (espec. pág. 281). Para V. VäÄNÄNRN (Introducción al latín vulgar, Madrid, Gredos, 1968, § 186) el valor instrumental es una consecuencia del sentido de posibilidad pasiva. La opinión de Hanssen es, en cambio, coincidente con la de M. Leumann (Die Lateinischen Adjektiva auf «-lis», Strassbourg, 1917).

9 Ibidem, págs. 282-285. Hay, además, derivados que son equivalentes a participios pasados de verbos transitivos; tal es el caso, según F. HANSSEN, de INMUTABILEM 
2.2. Estos sentidos de -Bflus perfilan la variedad significativa de sus descendientes $\mathrm{y}$, en particular, del -ble castellano ${ }^{10}$.

Las primeras documentaciones romances del sufijo aparecen ya en época temprana. R. Menéndez Pidal halla dos formas en diversas zonas de la Península:

aradiuiles (1056, Sahagún), aradeblis (1061, Leon; 1011, Sahagún), y mouebile (1111, San Juan de la Peña), moueble (1105, Sahagún; 1160, El Moral; 1233, Valladolid), moeble (1222, Valladolid) 11 .

Ambas poseen el sentido de posibilidad con valor pasivo, equivalente al de las actuales arables ('a propósito para ser aradas') y muebles -en la construcción bienes muebles - ('los que pueden trasladarse de una parte a otra' ${ }^{12}$ ). Pese a esta temprana aparición, el desarrollo de los derivados en -ble es más lento que el de otras formaciones y en una gran parte son latinismos.

En nuestros primeros textos literarios se registran frecuentes adjetivos con valor activo (sin expresar posibilidad o necesidad, o con los sentidos casual e instrumental):

durable, 'que dura' (< DURABllis, Berceo), perdurable (< PERDURABYlLIs, Berceo, Juan Ruiz, D. Juan Manuel) 13, estable (< STABILIs, Berceo), mudable (< MUTABlLIS, Libro de los exemplos) 14, placible (< PLAcibluIs, Ayala), variable (< VARIABYLIs, Libro de los exemplos) 15, conuenible (D. Juan Manuel, Libro de los exemplos), espantable (Juan Ruiz; en la Pri-

(= 'INMUtatus') en el siguiente ejemplo de Plauto: scio ouid ERRES: ouia VBSTITUM ATQUB ORNATUM INMUTABILEM HABET HABC (Ibidem, pág. 278).

10 En este aspecto es cierto, como afirma E. GaMILLSCHBg, que en la transmisión de un sufijo impera la función sobre su sustancia fónica (Grundzüge der romanischen Wortbildungslehre, Genève, Biblioteca dell'Archivum Romanicum, 1921, § 1).

11 R. Menéndez Pidal, Origenes del español, 7." ed., Madrid, Espasa-Calpe, 1972, $\S \S 47_{1}$ y $61_{6}$. En particular con respecto a este último interesa al autor su origen y, frente a C. H. GRANDGENT ( $₫$ El fr. meuble y esp. mueble suponen una $p$ en móvilis, que sería debida a la analogía de la $q$ de moveon, ob. cit., § 204) y E. StaAp (Etude sur l'ancien dialecte léonais d'après des chartes du XIIIe siècle, Uppsala, 1907, pág. 206) -como él mismo hace constar- propone como étimo movirbłlis, que permitiría explicar la existencia de las formas anteriores. Junto a éste, no obstante, мס̈llLs sería el origen natural de moble, que aparece, por ejemplo, en un documento castellano de 1196 ( $R$. MENḱNDEz PIDAL, Documentos lingultisticos de España, Madrid, CSIC, 1966, vol. I, doc. 17, pág. 40).

12 Siempre que sea posible, las definiciones pertenecerán al Diccionario de la lengua española de la Academia (19.* ed., Madrid, Espasa-Calpe, 1970), aunque en algunas ocasiones -como en ésta- nos permitiremos abreviarlas.

13 J. Corominas en su Diccionario crítico etimológico de la lengua castellana (Madrid, Gredos, 1954) lo documenta más tarde, en 1438, en J. de Mena.

14 Hacia la misma época, 1440 (Marqués de Santillana y Alfonso de la Torre), es registrado también por J. Corominas en su Diccionario.

15 Caso análogo al de mudable, para variable ofrece J. Corominas la fecha de 1438 (Corbacho de Martinzz DE Tolrdo y Coronación de J. DE MENa). 
mera Crónica General, en cambio, se da espauentable, formación latinizante), finable (Bonium), melezinable (Fazienda de Ultramar) 16, semejable (D. Juan Manuel, Libro de los exemplos; desemeiable en la Fazienda de Ultramar) 17, prestable (Berceo), saludable, 'que sirve para conservar o restablecer la salud' (Berceo), temorible, 'que produce temor' (Fazienda de Ultramar), terrible (< TERRIBluIs, Libro de los exemplos), pacibles ( $F a$ zienda de Ultramar; desapacible en D. Juan Manuel).

Frente a éstos, expresan posibilidad o necesidad pasivas:

donable, 'que merece la pena darlo' (< doNABlLIs, Juan Ruiz), comendable (< COMMENDABYlis, Libro de los exemplos), corrumptible (formado sobre CORRUMPERE por analogía con CORRUPTIBILIs, D. Juan Manuel), mirable, 'digno de ser admirado' (< murabilis, Berceo), notable (< NotaBlus, Libro de los exemplos), portable (< PORTABILIs, Baena, con el sentido del étimo latino: 'sufrible, soportable'), venerable (< VENRRABILIs, Libro de los exemplos), aborresçible (Libro de los exemplos), deseable (Berceo), leible (Berceo).

2.3. En el desarrollo y aumento de vitalidad de los derivados en - ble a partir de fines de la Edad Media debió influir decisivamente no sólo la incorporación de nuevos latinismos sino, sobre todo, la fijación de sus funciones ${ }^{18}$. A ello contribuyó la competencia de otros sufijos con valores semejantes.

El sufijo -ivo (-at/it-ivo), forma culta del latín -Ivus, da lugar a adjetivos al ser añadido a raíces verbales. Estos poseen como uno de sus sentidos habituales el de atribuir al sustantivo con que conciertan la «virtud o poder para verificar la acción del verbo primitivo* ${ }^{19}$. Dicho sentido constituye un freno en el sistema para el considerado valor primitivo de las formaciones en -ble, el instrumental (abortivo, confortativo, laxativo, etc.). Además, cuando esa capacidad para verificar la

16 Sustantivado en Sta. Maria Egipciaca (498):

$A$ las mjs llagas, que son mortales, non quiero otros melezinables

(señalado por J. J. DE Bustos, Contribución al estudio del cultismo léxico medieval, Madrid, Anejo XXVIII de la RFE, 1974, pág. 556).

17 J. J. DB Bustos registra el adjetivo simigible en un documento de 1236 de los editados por R. Menéndez Pidal (ibidem, pág. 689).

18 Análisis de este tipo, aunque referidos a otros formantes, pueden verse en: F. MONGR, «Sufjos españoles para la designación de 'golpe'», en Homenaje a Francisco Yndurain, Zaragoza, 1972, págs. 229-247, y -Ción, -sión, -zón y -ón: función y forma en los sufijos», en Estudios ofrecidos a Emilio Alarcos Llorach, Oviedo, 1978, vol. II, págs. 155-165; Suzanne Fleiscanun, «Factores operantes en la historia de un sufijo: el caso de 'azgo'», Ibidem, vol. I, págs. 75-85.

19 J. Almunx, Tratado de la formación de palabras en la lengua castellana, Madrid, L. Victoriano Suárez, 1920, pág. 96. 
acción del verbo, que en el sentido instrumental es virtual, se hace actual en el sustantivo, estos derivados convergen con los adjetivos con -ble en el valor activo: aflictivo (con tema participial de base) / afligible ${ }^{20}$.

Asimismo, el sufijo -oso, procedente del latín -osus, añadido a algunas raíces sustantivas, confluye en el sistema con las formaciones en -ble con valor causal (doloroso, frutuoso, litigioso, pavoroso, etc.), y al tomar como base temas verbales adopta valor activo (aprovechoso, desdeñoso, enojoso, mentiroso, etc.). En algún caso se produce la concurrencia de las derivaciones en -ble y -oso: lacrimable (Santillana) / lagrimosa (Nebrija, con sonorización de la velar oclusiva sorda [k]), espantable (Juan Ruiz) / espantoso (D. Juan Manuel) ${ }^{21}$.

Mayor es la vinculación que hay entre -ble y -dero. Este forma adjetivos que expresan la «posibilidad o necesidad de que la significación del verbo primitivo se cumpla en el sustantivo a quien se refieren» ${ }^{22}$. La analogía de sentidos con -ble explica que existan adjetivos con esos significados y valor pasivo (asadero, cobdiçiadero, deleznadero, fazedero, sofridero) y derivados - sin tal contenido- con valor activo (duradero, gritadero, parladero, pasadero). Las posibilidades combinatorias del sufijo son mayores en el español antiguo que en el moderno, de forma que en la actualidad - prescindiendo de otros sentidos que no confluyen con -ble - se usa, en general, con valor activo unido a verbos intransitivos ${ }^{23}$. Este proceso de reducción hace que mientras algunas formas en -dero perviven, en detrimento de las correspondientes en -ble (duradero/*durable, casadero/*maridable), otras sufren el fenómeno inverso (deleznable/*deleznadero, codiciable/*cobdiçiadero, factible/*fazedero) ${ }^{24}$.

20 Aflictivo es declarado anticuado por la Academia desde 1884 (S. Gill GaYA, Tesoro Lexicogrdfico, Madrid, CSIC, 1947-1952, s. v.) y como tal continúa en la 19." del Diccionario académico.

21 El mismo significado activo es tomado por los derivados en -izo (< -icrus) cuando el sufijo se añade a temas participiales: caedizo, espantadizo, huidizo, movedizo, olvidadizo, etc., aunque estas formaciones, principalmente cuando proceden de un verbo perfectivo, suelen adoptar sentido frecuentativo.

2 J. Alemany, ob. cit., pág. 42.

23 No cabe, sin embargo, pensar que los derivados en -ble y -dero se hallan en distribución complementaria. Así, en la actualidad, junto a casadero, duradero, perecedero o venidero, se registra, por ejemplo, pagadero (distinto del pagadero que, con el sentido de 'agradable' se documenta en el Conde Lucanor de D. JUAN MANUEL).

24 Véase F. Diez, ob. cit., pág. 327. También hay que tener en cuenta los participios de presente, cuyo sentido activo confluye con derviados en -dero en competencia con los adjetivos equivalentes en -ble. Se explica asi la existencia de formaciones con -ble perdidas en favor de los participios: conuenible/conveniente, semejable/semejante. 
Esta interrelación de sufijos permite el crecimiento de los adjetivos en -ble caracterizados por expresar posibilidad o necesidad con valor pasivo ${ }^{25}$.

3. Las formaciones en -ble en el estadio sincrónico actual no constituyen un subsistema perfecto en cuanto a su homogeneidad. El hecho de que la diacronía se imbrique en la sincronía explica la existencia de términos que no se ajustan a esquemas o procesos regulares. Por ello, junto a derivaciones características del español moderno, se hallan otras cuya configuración formal o cuyo contenido es producto de estadios anteriores.

Además de derivados formados sobre base verbal hay también adjetivos en -ble que proceden de una base sustantiva. Entre éstos, mucho menos numerosos que los primeros, cabe mencionar: bonancible (derivado de bonanza < ${ }^{\star}$ BONACIA ${ }^{26}$ ), saludable (creado sobre salud) y -con criterio amplio- viable (galicismo del siglo XIX formado sobre vie con el sentido de 'que tiene condiciones de vida', aunque, actualmente, el sentimiento linguístico de los hablantes tiende a considerarlo derivado de via) ${ }^{27}$; desusados son, por ejemplo, canonjible (formado a partir de canonje, préstamo medieval del occitano canonge) y manuable (derivado procedente del cruce de manual con manejable y formado sobre la base de mano) ${ }^{23}$. En general son vocablos que tienden a adquirir alguna

25 Es un hecho reconocido la existencia de relación entre estos términos y la diátesis pasiva (con planteamientos diversos véase J. DuBors, Grammaire structurale du français: la phrase et les transformations, Paris, Larousse, 1969, chap. VI y W. Abraham, aPassiv und Verbalableitung auf e. -able, dt. -bar», Folia Linguistica, IV: 1/2, 1970, págs. 38-52). S. KüRDE señala que estos adjetivos son uno de los medios de que dispone la lengua para expresar la idea de un sujeto indeterminado - general, lo que le permite entroncarlos con la pasiva pronominal (Quelques manières d'exprimer l'idée d'un sujet indéterminé ou général en espagnol, Uppsala, 1943, pág. 86). Por ello, y dada la importancia de los verbos modales en el desarrollo de la pasiva pronominal en español antiguo (véase ibidem, chap. V y F. Monge, «Las frases pronominales de sentido impersonal en español», Archivo de Filología Aragonesa, VII, 1955, págs. 7-102), cabría pensar en la relación entre la fijación del valor modal pasivo en los derivados en -ble y el desarrollo de estructuras oracionales equivalentes.

26 El étimo propuesto por J. Corominas halla apoyo en la documentación de bonacible en el Tesoro de Sebastián de Covarrubias.

27 Distinto es el caso de confortable, término llegado a través de la influencia del francés y el inglés. Es ya comentado por R. M." Baralt en su Diccionario de galicismos (Madrid, Imprenta Nacional, 1885), incorporado al Diccionario de la Academia en su 16." edición (1939) y examinado por R. J. Alfaro en su Diccionario de anglicismos (2." ed. aum., Madrid, Gredos, 1970), quien resalta la anomalía de la acepción de 'cómodo', hecho también subrayado por J. Corominas (ob. cit., s. v. fuerte).

28 Pese a que J. Corominas lo fecha en 1914, aparece ya entre los ejemplos citados para el espańol por F. DIEz (ob. cit., pág. 305). 
independencia léxica - salvo quizá saludable ${ }^{2}$, de tal modo que difícilmente toman el sentido esperable de términos sufijados ${ }^{30}$.

Los derivados que proceden de base verbal presentan anomalías de índole formal y significativa. Formalmente, los adjetivos - latinismos o no- cuya base existe en el repertorio léxico de la lengua ofrecen una derivación temática, esto es, el sufijo se une a la base mediante un elemento temático: -a-para los adjetivos formados sobre verbos de la denominada primera conjugación (en -ar) e -i- para los de la segunda y tercera (en -er e -ir): abarcar $\rightarrow$ abarc-a-ble, aborrecer $\rightarrow$ aborrec-i-ble, servir $\rightarrow$ serv-i-ble ${ }^{31}$. No en todos los casos se puede, sin embargo, establecer este tipo de derivación simple. Hay adjetivos cuya base hay que buscarla en temas participiales latinos (admisible, comprensible, corrosible, etc.), aunque existan correlatos verbales ${ }^{32}$.

29 En este sentido, mientras que la definición proporcionada para saludable por el Diccionario académico ('Que sirve para conservar o restablecer la salud corporal') asocia el adjetivo a su base, la dada para bonancible ('Tranquilo, sereno, suave') prescinde del sustantivo de origen.

30 Otra es la situación de neologismos recientes como alcaldable, ministrable o rectorable (formados sobre alcalde, ministro y rector, respectivamente), que parecen creados por analogía con papable, préstamo del italiano papabile. Véase $\S 4.2$.

31 Se trata, pues, de la misma vocal temática de las formas participiales (abarcado, aborrecido, servido), vocal que no consideramos elemento vacío, sino -coincidiendo con C. F. HockETT - como un morfema athe meaning of which is something submorphemic in the structure of the language» (Peiping Morphophonemics», Language, 26, 1950, págs. 63-85: n. 6). Los adjetivos terminados en -eble, -oble y -uble (endeble, noble, soluble) proceden directamente del latín y no cabe reconocer en ellos un proceso derivativo en términos sincrónicos.

32 Recientemente, la fonología generativa ha insistido en el intento de someter estas variantes a procesos derivativos regulares mediante reglas morfo(fo)nológicas. No es un intento nuevo -recuérdese, aunque con sentido distinto, la tradición praguense - ni carente de críticas, de las que una de las más importantes es no vincular directamente la configuración morfo(fo)némica a la representación fonética (véase A. Martinet, «De la Morphonologie», Linguistique, I:2, 1965, págs. 15-30 y J. VACHEx, «Prague Phonological Studies Today», TLP, I, 1964, págs. 7-20). Se parte para ello de la posibilidad de establecer alternancias paradigmáticas como las siguientes: -T/-S (admit-ir/admis-i-ble), -D/-S (divid-ir/divis-i-ble), -B/-PT (prescrib-ir/ prescript-i-ble), -ND/-NS (comprend-er/comprens-i-ble), -OMP/-UPT (corromp-er/ corrupt-i-ble), - $\Theta /-\mathrm{KT}$ (reduc-ir/reduct-i-ble), válidas en gran parte para otros tipos de derivaciones: admisión, división/divisor, comprensión/comprensivo, corruptor, reductor (un análisis clásico puede consultarse en J. W. HARRIS, Fonología generativa del español, Barcelona, Planeta, 1975, cap. 5). Es claro, no obstante, que la perspectiva diacrónica desmiente esta generalización: mientras que las alternancias -T/-S y -ND/-NS, por ejemplo, hay que estimarlas pertenecientes a la raiz en los pares verbo-derivado en -ble, no cabe tal posibilidad en los correspondientes verbonombre de acción, dada la existencia del sufijo latino -SIONE (paralelo a -TIONE). Llevando el planteamiento a su extremo, y al margen de otras consideraciones, son indudables las dificultades que plantearía explicar, por ejemplo, fugitivo (o el ant. fugible) a partir de huir. Con otro planteamiento, M. ARONOFF distingue los 
En cuanto a su significado, es opinión generalizada que el sufijo -ble, añadido a raíces verbales, da lugar a adjetivos que expresan el modo de ser del objeto que conlleva el predicado verbal ${ }^{33}$. Prescindiendo por ahora de la función del sustantivo concordante en la oración correspondiente, parece que en todos los casos es posible atribuir al sufijo un sentido que permite asociar paradigmáticamente el derivado adjetivo a su base verbal. No obstante, hay términos, que se apartan de esta regla general, en los que el sufijo, pese a ser delimitable distribucionalmente ${ }^{34}$, no lo es significativamente.

El ejemplo más claro lo constituyen los derivados que han sufrido un proceso de especialización semántica y han llegado a cambiar de categoría. Son sustantivos como contable, dirigible, sumergible, etc., formas que coexisten con sus homófonas adjetivas:

El dirigible cayó incendiado sobre la ciudad

Este proyectil es dirigible desde tierra.

Parcialmente semejante es la situación de adjetivos como, por ejemplo, amable, considerable o respetable. Mientras que el sufijo se puede delimitar formalmente, el sentido de los derivados, en mayor o menor dependencia del significado de la base, no corresponde a los esquemas de derivación regulares. Se trata de adjetivos en los que se han desarrollado especificaciones secundarias que impiden considerarlos derivados con un criterio estricto. Así, amable es un adjetivo apreciativo que significa 'afable, complaciente, afectuoso', considerable presenta valor cuantitativo ('grande, cuantioso') y respetable se usa ponderativamente en frases como Le mostro una cantidad de dinero respetable o El ganador saco una ventaja respetable al resto de los corredores.

4. Acotado así el campo de análisis interesa destacar que las formaciones en -ble no constituyen en espafiol actual un grupo homogéneo en

afijos \# abl y $+a b l$. Se trata de una diferencia de junción, pues, lo que le permite distinguir sufijos. Esta distinción se justifica morfológica, sintáctica y semánticamente. En el plano morfológico \# abl tiene base verbal, mientras que $+a b l$ no tiene base (perceivable/perceptible). Sintácticamente, \# abl se vincula estrechamente $a$ un esquema general, $+a b l$, en cambio, no responde claramente a una norma arquetípica. Desde el punto de vista semántico, \# abl está próximo a la composicionalidad significativa, al contrario que $+a b l$, que posee sentidos que lo alejan del carácter composicional. En último término, como sefiala el autor, la diferencia que existe entre los dos afijos es sólo de grado (Word Formation in Generative Grammar, Cambridge, The MIT Press, 1976, chap. 6).

33 Véase J. Alemany, ob. cit., pág. 36.

34 Para la definición formal del sufijo, en términos distribucionales, véase $R$. MArTiN, «A propos de la dérivation adjective: Quelques notes sur la définition du suffixe», Travaux de Linguistique et de Littérature, VIII:1, 1970, págs. 155-166 (espec. pág. 162). 
cuanto a la base en que se apoya la derivación. La mayor parte de los estudios realizados aceptan, explícita o implícitamente, que se trata de adjetivos de origen verbal. Sin embargo, como ya hemos señalado, estos adjetivos se distribuyen en dos tipos según la categoría de la base: derivados procedentes de base verbal y derivados formados sobre base sustantiva.

4.1. Como ya se ha apuntado, el formante -ble se anfade habitualmente a bases verbales transitivas. El adjetivo resultante tiene sentido modal y se refiere al sustantivo que en la oración correspondiente desempeña la función de objeto directo ${ }^{35}$. Esta formulación general del sentido de estos derivados queda bastante diversificada en las definiciones que, por ejemplo, ofrece el Diccionario académico. A partir del mismo es posible establecer los siguientes tipos fundamentales:

(1) $x$ es Adj (-ble) $=$ ' $x$ puede V-se' aconsejable, 'que se puede aconsejar'

(2) $\mathrm{x}$ es Adj (-ble) = 'x es capaz de V-se' plegable, 'que es capaz de plegarse'

(3) $x$ es Adj (-ble) $=$ ' $x$ puede o debe V-se' discutible, 'que puede o debe discutirse'

(4) $x$ es Adj (-ble) $=$ ' $x$ es fácil de $V$ ' impresionable, 'que es fácil de impresionar'

(5) $x$ es Adj (-ble) = ' $x$ merece V-se' desdeñable, 'que merece ser desdeñado' aborrecible, 'digno de ser aborrecido'

El formante -ble se une también a bases verbales intransitivas. En este caso el adjetivo derivado se refiere al sujeto ${ }^{36}$. Consecuentemente, tiene valor activo, si bien no hay regularidad en cuanto a la presencia o ausencia de contenido modal:

(6) $x$ es Adj (-ble) = ' $x$ V' perdurable, 'que perdura'

(7) $x$ es Adj (-ble) $=$ ' $x$ puede $V$ ' servible, 'que puede servir'.

35 Puede asimismo referirse al «suplemento» verbal $\rightarrow$ con término de E. Alarcos ( Verbo transitivo, verbo intransitivo y estructura del predicado», Estudios de gramática funcional del español, Madrid, Gredos, 1970, págs. 109-123)- de la oración correspondiente: Tiene poco tiempo disponible $(\leftarrow$ Tiene poco tiempo del que puede disponer). Ello no supone un caso esencialmente distinto al del objeto directo («implemento» de E. Alarcos), dado el paralelismo existente entre ambos, como muestra el mismo autor.

36 Adjetivos como navegable, transitable o esquiable se refieren, en cambio, a un circunstancial locativo y son asimilables a los que modifican al objeto directo. 
Ante la variedad de sentidos de estos derivados cabe preguntarse si es posible delimitar una categoría significativa básica que los unifique y fijar los factores que determinan la aptitud de un adjetivo para adoptar un valor dado.

Es indudable que, si tomamos como referencia los casos más frecuentes, no parece inadecuado considerar este sufijo como una de las formas de expresión de la modalidad ${ }^{37}$. Cierto es que los adjetivos formados sobre verbos intransitivos no presentan con carácter general dicho contenido. No obstante, se puede observar, de una parte, que los ejemplos que ofrecen esta particularidad son casi todos latinismos:

estable, 'constante, durable, firme, permanente' ( $<$ staBllis), mudable, 'que con gran facilidad muda' (< MUtaBllis), perdurable, 'perpetuo o que dura siempre. - 2. Que dura mucho tiempo' (< PERDURABllis), variable, 'que varía o puede variar' ( $<$ VARIABłlLIS).

De otra, cabe señalar que en neologismos recientes del mismo tipo aparece el contenido modal, como ocurre en vivible, referido al circunstancial locativo que conlleva el predicado ${ }^{38}$.

El sufijo -ble, en cuanto formante productivo, atribuye a los adjetivos derivados valores que se hallan relacionados con los verbos modales, relación que de formas diversas es puesta de relieve en las definiciones de dichos derivados.

La analogía de sentido con tales verbos, sin embargo, no parece clara para las formaciones que responden a la paráfrasis ' $x$ merece $\mathrm{V}$-se'. Tal sentido es característico de adjetivos como abominable, admirable,

37 En los estudios modernos, el análisis de la modalidad cobra relevancia con Cr. Bally. Para este lingliista suizo ala modalité est la forme linguistique d'un jugement intellectuel, d'un jugement affectif ou d'une volonté qu'un sujet pensant énonce à propos d'une perception ou d'une représentation de son esprit» («Syntaxe de la modalité explicitex, Cahiers Ferdinand de Saussure, 2, 1942, págs. 3-13: pág. 3). La modalidad (modus) se manifiesta de forma explícita, independiente del dictum, mediante verbos modales (Je crois qu'il pleut, Hoy puede nevar) o implícitamente, a través de adverbios, adjetivos o modos verbales comprendidos en el dictum. En este planteamiento, como bien señala A. MEUNIER («Modalités et communication», Langue française, 21, 1974, págs. 8-26), el modus agrupa hechos distintos. Es preciso diferenciar la «modalidad de la enunciación», que se relaciona con el emisor y caracteriza necesariamente una frase como declarativa, interrogativa, etc., y la "modalidad del enunciadon, que se relaciona con el sujeto del enunciado y permite caracterizar éste en relación con las nociones de verdad, necesidad, posibilidad u otros juicios apreciativos. Aunque por otro camino, a una distinción básicamente análoga había llegado A. Garcfa Calvo al estudiar diversas oposiciones verbales en el griego antiguo ( Preparación a un estudio orgánico de los modos verbales sobre el ejemplo del griego antiguo», Emerita, 28, 1960, págs. 1-47).

38 Su utilización la hallamos en Las ninfas de F. UMBral: *una ciudad distinta, más culta y apacible, más antigua y vivible» (Barcelona, Destino, 1976, pág. 25). 
aborrecible, adorable, apetecible, deplorable, despreciable, detestable, envidiable, execrable, menospreciable, respetable, reprobable o venerable. Este contenido, stricto sensu, no puede ser incluido en el ámbito de los sentidos de deber. Representan un tipo de modalidad apreciativa en tanto en cuanto revelan un juicio valorador de índole subjetiva. Lo expresado por tales adjetivos es presentado como requerido o necesario para el sustantivo al que se refieren. Pero, además, esta relación supone un proceso virtual en el derivado, cuya realización es concebida en dependencia de una voluntad ajena a la del sujeto. Así, una decisión respetable denota 'una decisión que es digna de ser respetada', y esta denotación entraña el deseo de realización de un proceso ('llegar a ser respetado') que depende, no del hablante, sino de la voluntad de aquellos a quienes se apela.

Esta caracterización concuerda con la naturaleza de los verbos de los que proceden dichos adjetivos. Se trata de verbos que contienen un juicio de valor hacia algo o alguien y para cuyo agente se presupone la experimentación del mismo (de ahí la posibilidad de la paráfrasis 'x siente abominación /.../ por $\mathrm{y}^{\prime}$ ).

La mayor parte de los adjetivos formados con -ble poseen sentidos análogos a los de poder. Admiten, pues, las interpretaciones de 'permiso' - la menos frecuente-, 'capacidad' y 'posibilidad'. En cada caso la selección de un sentido determinado depende, en general, del contexto:

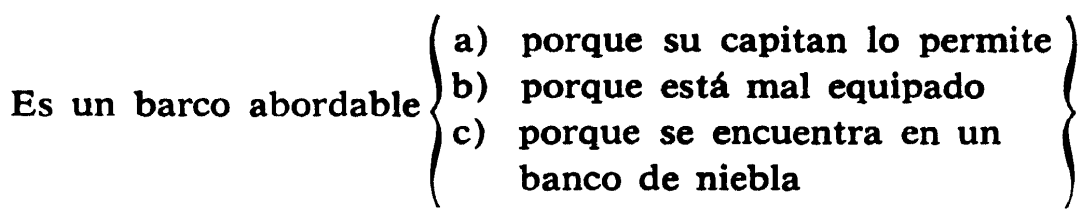

a) La policia permite que sea un paso franqueable.

b) Al ser una zona calcárea es fácilmente franqueable.

c) Si no ha habido desprendimientos, será un barranco franqueable.

Cuando el contexto o lo consabido por los hablantes no proporcionan datos suficientes para discriminar un sentido preciso, los valores posibles se neutralizan. El adjetivo, entonces, expresa la simple potencialidad para realizar un proceso de cambio de estado.

No siempre es posible, sin embargo, la triple interpretación de estos derivados. De una parte, hay adjetivos como absorbible, coagulable, digerible o evaporable que no admiten el sentido de 'permiso'. Son adjetivos formados sobre verbos cuya estructura de valencias semánticas excluye lógicamente la presencia de un causativo personal. De otra, los adjetivos derivados de verbos con objeto del tipo eeffectum» no per- 
miten la interpretación de 'capacidad': edificable ${ }^{39}$, ejecutable, elaborable, fabricable, inventable, realizable. Ello es natural dado que los términos de base se refieren, no a acciones que afectan o se aplican a un objeto ( affectum»), sino a acciones que llevan consigo la actualización del mismo. Consecuentemente, el desarrollo del proceso implicado por el derivado no puede estar determinado por características inherentes al objeto 10 .

Superpuestas a este significado básico los adjetivos en -ble pueden desarrollar especificaciones semánticas secundarias. En este sentido, por ejemplo, respirable no expresa sólo 'que cabe ser respirado', sino 'que se puede respirar sin daño de la salud' "1. Entre estos rasgos adicionales merece destacarse el de 'facilidad', que representa una vertiente intensiva de la modalidad de poder. Este sentido aparece con regularidad en los adjetivos que proceden de dos tipos de verbos. Es característico, en primer lugar, de los derivados formados sobre verbos con estructura semántica causatica cuyo objeto directo es un experimentador: desmoralizable, excitable, impresionable, irritable. En segundo lugar, este rasgo lo ofrecen también adjetivos como pronunciable o manejable, derivados de verbos que exigen un agente del que se presupone la capacidad necesaria y suficiente para realizar la acción denotada por los mismos. En los dos casos, el argumento que lleva a cabo el proceso posee cualidades inherentes que favorecen su realización. La posibilidad se da por supuesta y pasa a primer plano el sentido reflejado por la paráfrasis ' $\mathrm{x}$ es fácil de V'.

Es frecuente, además, que un derivado pueda recibir más de una interpretación. Se producen, así, alternancias de los valores de poder y los de merecer o deber. En unos casos, tales valores se distribuyen según las acepciones del verbo de procedencia, como en apreciable o estimable: si el adjetivo remite a la interpretación del predicado como proceso psíquico ('Reconocer el mérito de las personas o de las cosas', 'Hacer estimación de una persona o cosa'), adopta el sentido de ' $x$ merece V-se'; si el verbo de base es entendido en su acepción cuantitativa ('Poner precio o tasa a las cosas vendibles', 'Valor que se da o en que se tasa una cosa'), el adjetivo tiene el sentido de poder. En la mayoria de los

\footnotetext{
39 No presenta este sentido cuando se refiere a un sustantivo que en la oración equivalente desempeña la función de circunstancial locativo, caso equiparable al de transitable, etc., como en la construcción zona edificable.

- A la inversa, la existencia de rasgos inherentes en el objeto determina el sentido de 'capacidad', como en plegable o flexible.

41 Adviértase que análogo sentido posee también comestible. A este valor pueden añadirse usos especificos de términos empleados técnicamente, como, por ejemplo, cantable, 'que se canta despacio'.
} 
ejemplos, no obstante, el valor de los derivados en -ble está determinado por el contexto y la intención del hablante.

4.2. La formación de derivados en -ble sobre base sustantiva da lugar a un número escaso de adjetivos. Con todo, este tipo de formaciones permite observar que el sufijo -ble ${ }^{42}$ ha ampliado sus posibilidades de combinación. Ejemplos recientes que prueban tal extensión son adjetivos como noticiable ('digno de ser noticia'), presidenciable ('susceptible de estar en la presidencia'), ministeriable ('susceptible de estar en un ministerio') en competencia con ministrable ('susceptible de ser ministro'), manicomiable ('susceptible o digno de estar en un manicomio'), etc.:

(...) es automáticamente un perfecto ministeriable (Cuadernos para el diálogo, n. ${ }^{\circ}$ 97, oct. 1971, pág. 15a)

En el Madrid de los ejecutivos, los tecnócratas, los ministrables (...) (F. Umbral, Diario de un snob, Barcelona, Destino, 1978, pág. 47)

Fue un cotarro prácticamente manicomiable (Informaciones, 22-I-1973, pág. 14)

12 Consideramos, pues, que se trata de un solo sufijo, frente a lo propuesto por M. Aronoff para el inglés, quien, apoyándose en la hipótesis de que la especificación sintáctico-semántica de la base es siempre única, distingue dos sufijos \# able: $\mathbf{N}$ \# able (fashionable, sizable) y V \# able (acceptable, doable). En favor de esta distinción aduce tres argumentos: (a) ambos se forman por reglas distintas; (b) $\mathrm{N}$ \# able siempre admite \# ness y nunca + ity (sizableness, sizability), mientras que $\mathrm{V}$ \# able no muestra preferencia por uno u otro (acceptability, acceptableness); (c) los dos \# able difieren en su significación: V \# able, 'capaz de ser Xado' / $\mathrm{N}$ \# able, 'caracterizado por $\mathrm{X}$ ' (ob. cit., § 4.1.1.). La distinción establecida por M. Aronorf, al menos para el espaniol, nos parece inadecuada. Prescindiendo de la compatibilidad con otros sufijos -irrelevante en nuestra lengua - y de los aspectos derivativos propios de marco teórico en el que se encuadra el estudio, no vemos razones suficientes para diferenciar dos sufijos homófonos -ble. Es cierto que alcaldable y aconsejable, por ejemplo, responden a diversos esquemas de formación, determinados por la naturaleza categorial del término de base. En cambio, funcional y significativamente el sufijo presenta el mismo comportamiento en ambos casos. Frente a lo señalado por M. Aronofr en inglés, el sufijo -ble posee en los dos casos valores análogos, vinculados a la expresión de la modalidad: 'susceptible de ser alcalde', 'que puede aconsejarse'. En los dos tipos, pues, el derivado entraña un proceso virtual de cambio hacia un estado o cualidad. Por ello, si bien los adjetivos como alcaldable o aconsejable proceden formalmente de bases distintas, estimamos que adquieren contenido modal en virtud de la incidencia del sufijo sobre un componente predicativo. En consecuencia, si para los derivados formados sobre base verbal tal componente aparece explícito en la misma, para los procedentes de sustantivo hay que suponerlo implícito. En otros términos, cabe considerar que el sustantivo se halla inserto en un esquema oracional ideal en el que es el núcleo semántico, es decir, en una estructura atributiva (alcaldable $\leftarrow$ ser alcalde + -ble). Esta derivación, así entendida, entronca con el desarrollo de E. CosERIU ( «Las estructuras lexemáticas», Principios de semántica estructural, Madrid, Gredos, 1977, págs. 162-184: § 4.2.1.). 
(...) se levantaban expresiones pulpitables (R. M.^ del Valle-Inclán, Viva mi dueño, Madrid, Espasa-Calpe, 1961, pág. 189)

Los atracadores buscan casi siempre dinero $u$ objetos fácilmente dinerables (Hermano Lobo, n.0 70, 8-IX-1973, pág. 1).

José Francisco Val álvaro 